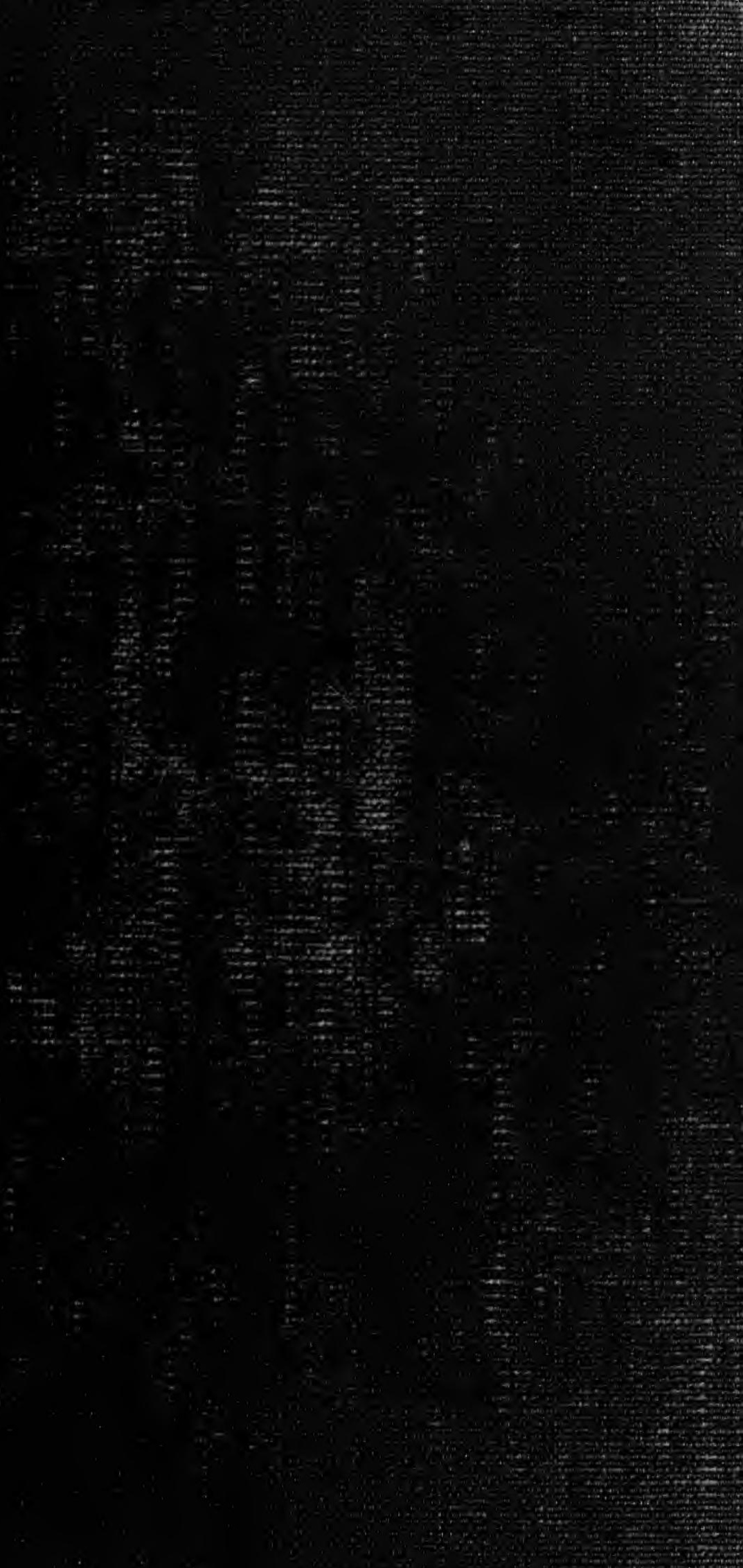




\section{The}

Mluiversity, of Batiformia
Sitruny
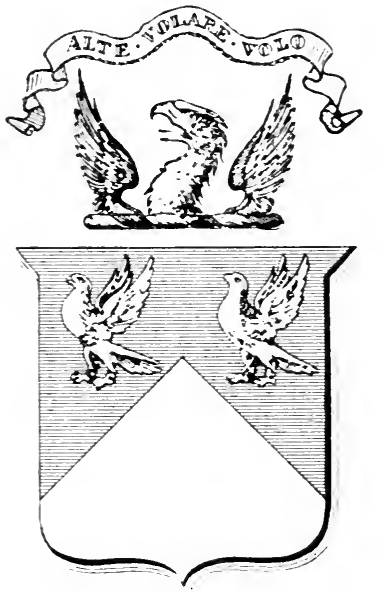

He Mlorse Stephens

Orversuty of Galifornie 

MEMRY MORSE STEPHER $\because: \because: \quad: \because \because: \because: \vdots \vdots: \vdots$ 
HENRY MORSE STEPHENS COLLECTION .

\author{
PAMPHLETS \\ ON \\ CALIFORN IA.
}

1. Brown, John Leander. Earthquake blessings. 1906

2. Chapman, Charles E. The Alta California supply ships, 1773-76. 1915

3. Davidson, George. The

Discovery of Humboldt Bay, California. 1891

4. Davis, John F. The History of California. 1915

5. Holway, Ruliff S. The Effect of seven years' erosion on the California fault line of 1906. 1914

6. Hunt, Nancy A. By Ox-team to California. 1916

7. Miller, E. I. A New departure in county government. 1913

8. Southern Pacific Company. San Francisco, the imperishable. 

9. Teggart, Frederick J. The Approaches to California. 1912

10. Woolley, Lell Hawley.

California 1849-1913. 1913 



\section{THE EFFECT OF SEVEN YEARS' EROSION ON THE CALIFORNIA FAULT LINE OF 1906}

RULIFF S. HOLWAY

University of California

REPRINTED FROM THE

Bulletin of the American Geographical Society Vol. XLVI., JUNE, I 9 I 4 
HEARY MURSE STEPMERS 


\title{
THE EFFECT OF SEVEN YEARS' EROSION ON THE CALIFORNIA FAULT LINE OF 1906
}

\author{
By RULIFF S. HOLWAY \\ University of California
}

The persistence for more than seven years of the minor surface features due to horizontal movement in 1906 along the San Andreas Fault has led to expressions of surprise even from some widely known students of earth forms. The movement in the part of the fault $z \mathrm{e}^{1}$ to be discussed was practically horizontal and was in a region where no bare rock outerops. At the time of the last faulting the land was largely a pasture interspersed with occasional small patches of low brush. The surface features due to the differential horizontal movement on the two sides of the fault plane are made largely by the fracturing and erumpling of the sod, frequently resulting in a low ridge such as that shown in Figure 2. The elevation of the ridge is slight, usually varying from a few inches to one or two feet above the general level. The width of this ridge is from three to ten feet. It was naturally expected that erosion would cause a rapid lowering of the little hummocks of the fault trace because of their small size, steep slopes, and exposure of unprotected soil in the breaks. Notwithstanding the softness of the material, observation now shows that at the present time, January, 1914, after seven years of rainfall, the fault trace in unplowed land may be followed as certainly and with nearly as little effort as it was followed in April, 1906. Recent plowing of the area shown in Figure 2 necessitates that comparison be made with the present aspect of the fault trace as it appears on the nearest slope with similar conditions. Figure 3, however, represents no exceptional instance of the present appearance of the fault trace, as it is one of six photographs taken during an hour's walk, all of which show the low ridge with equal clearness, the choice of Figure 3 being based on the elosest approximation of the slopes to those in Figure 2. It will be seen that the main effect of the seven years' erosion has been merely the softening and rounding of the sharp edges of the broken sod. The fact that different localities are

1 The San Andreas Fault emerges from the sea about ten miles south of the Golden Gate at Mussel Rock, a point designated on the San Mateo sheet, U. S. topographic map, and shown on Figure 1. The trace of the fault for the next four or five miles southeasterly along the hill tops is the portion directly considered in this paper. 
represented in the figures precludes any estimation of the amount of reduction of the general elevation of the ridge as a whole.

Any surprise at this persistence of the minor surface features is not to be taken as an indication that the facts here described controvert opinions formed from proper consideration of the problem, for it may be merely the unconscious effect of the modern scientific riew that all topographic forms are ephemeral phases in the geographic cycle. The problem has receired but little attention

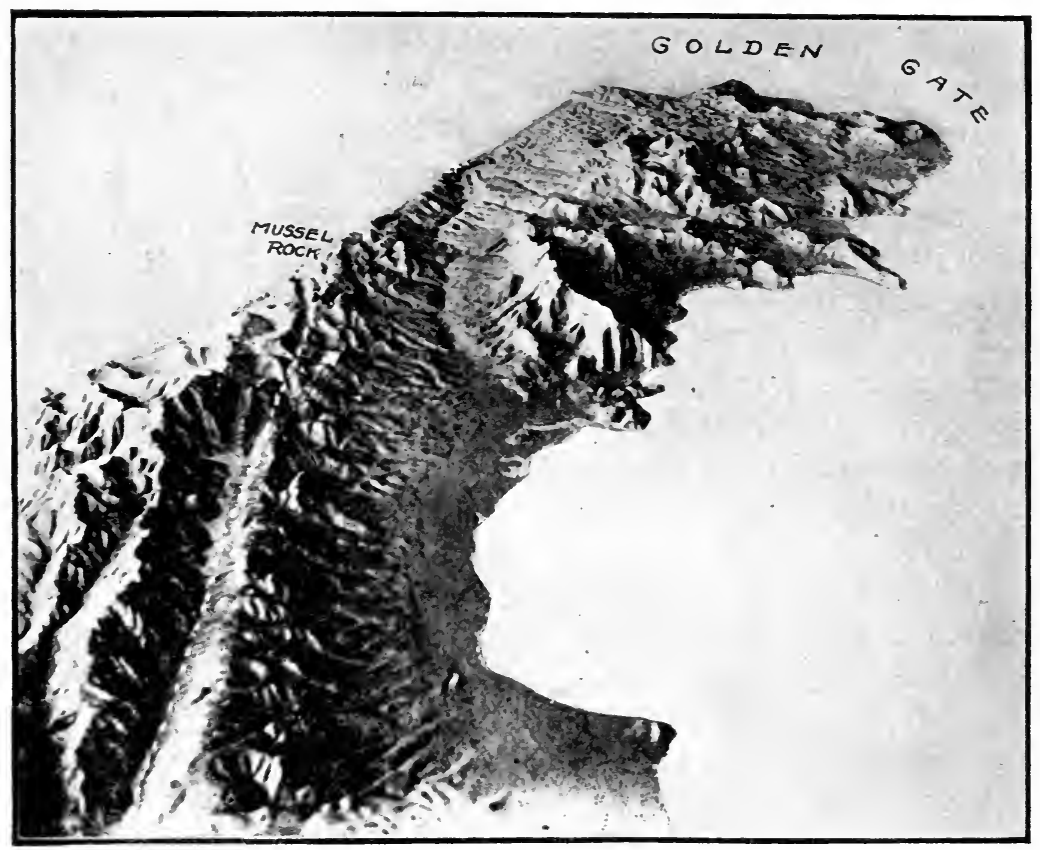

FIG. 1-Perspective View of a Model of San Francisco Peninsula. The coast line on which Mussel Rock lies runs almost due north and south; the Golden Gate trends east and west. The trace of the 1906 fault is shown by the line dotted in white. Original model by Professor A. C. Lawson.

hitherto, but the approximate determination in years of the period for the complete obliteration of the fault trace-both irregularities and ridge-is becoming a question of considerable interest and even of practical importance in the study of a region where faulting is frequently manifest at the surface. The only reference to the problem thus far noted is by Dr. G. K. Gilbert in his description of a portion of the San Andreas fault zone lying to the north-west of San Francisco. 
"The fault-trace, however, is a relatively perishable and transient phenomenon and its preservation might have comparatively definite meanings. At two localities I thought I discovered old 'traces' of the ridge type.... The features are....too indefinite to be recognized in the [photographic] view. If these old traces have been properly identified they are of very moderate antiquity. I should suppose that the ridges of the recent trace would lapse to such a condition in four or five years and that they might persist, under pasture conditions, for two or three decades.",

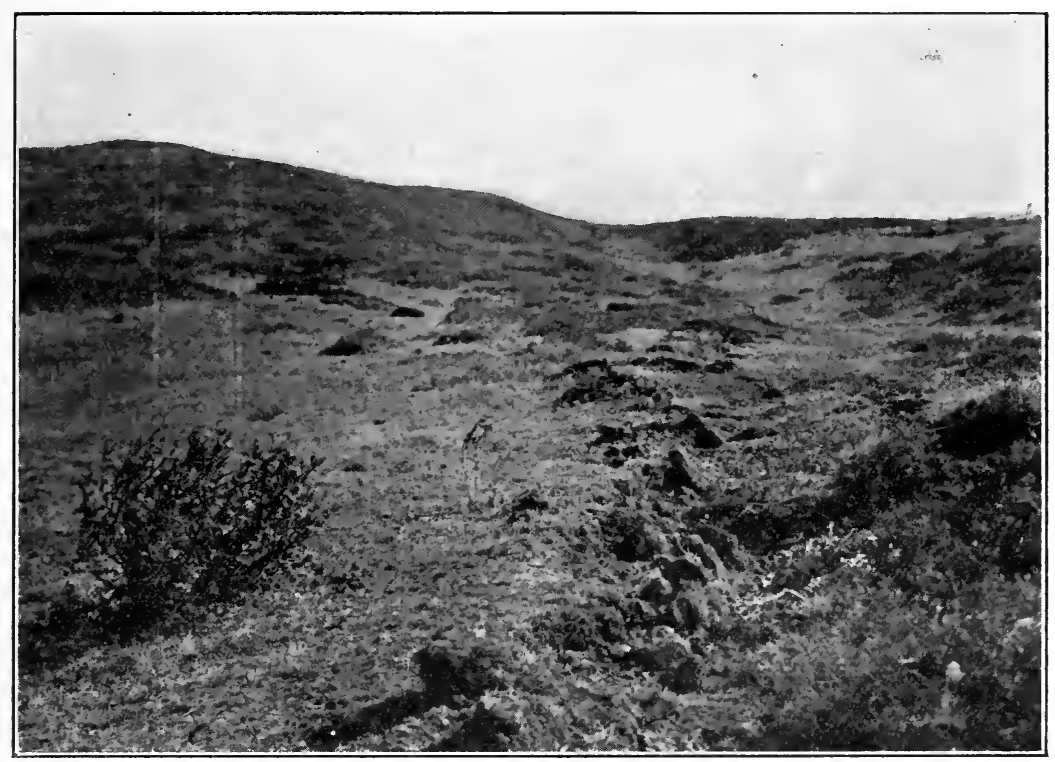

FIG. 2-Trace of the San Andreas Fault as it appeared in 1906.

The condition of the fault trace at the present time indicates that the estimated period of four or five years is entirely too short, for "traces" of the ridge type to become so obscure as not to be recognized with eertainty, for they are plainly evident in photographs taken after the expiration of seven years. The writer judges that there is strong probability that they will continue to be unmistakable for quite a number of years to come. The particular section of the rift under consideration has been traversed by the writer once or twice every year since 1906. The greatest change, the softening of the sharp edges of the broken sod, occurred, very

2 The California Earthquake of April 18, 1906, Vol. I, p. i3. Carnegie Institution, 1908. 
naturally, during the first two winters. From the physiographic standpoint it is unfortunate that the growth of San Francisco has caused the regetable gardens to be pushed constantly southward and that much of the pasture land through which the rift passed is being brought under cultivation. The probability grows stronger that man will erase all features in this portion of the fault zone long before erosion would have obliterated them.

More distant sections of the rift to the northwest may be.less

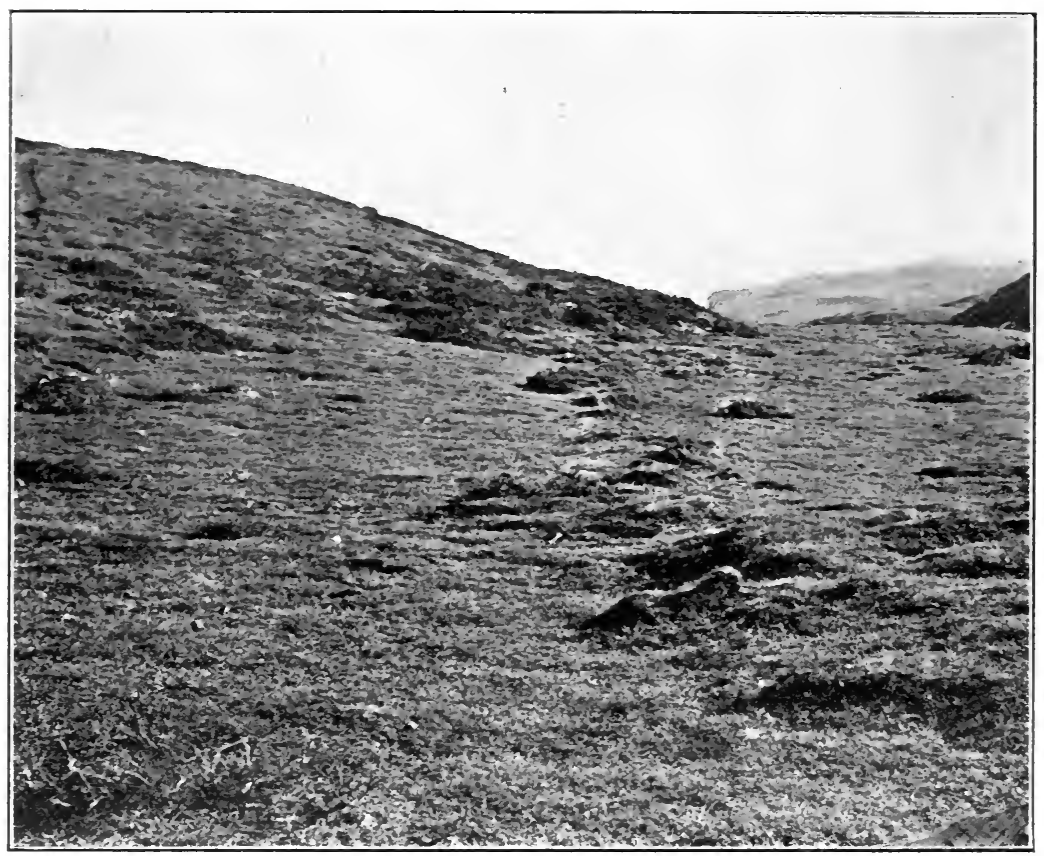

FIG. 3-Trace of the San Ardreas Fault as it appeared in November, 1913. This locality is a little orer a mile southeast of that in Figure 2, which has been plowed during the past year.

disturbed. It is hoped that somewhere along the fault zone at intervals of a few years careful observations may be made, supplemented by photographs which will show the successive stages in the process of final obliteration of the fault trace.

About eighteen miles distant from and approximately parallel to the San Andreas Fault is another known as the Haywards Fault. Movement along this line in 1868 resulted in a crack manifest at the surface for some twenty miles. The retracing of this line by observers having in mind the criteria furnished in April, 
1906, has not resulted in any report of the present existence of remains of a fault trace similar to that shown in Figure 2. However, the two fault movements are probably not comparable. The incomplete records of the 1868 movement on the Haywards Fault indicate that the horizontal movement, if it occurred, did not exceed three feet, while the movement in the San Andreas Fault in 1906 reached a maximum of twenty-one feet. It should also be remembered that along the 1906 rift the size and definiteness of the fault trace varied greatly in short distances and with the slope of the land. Consequently the failure to find signs of the fault trace of 1868 still existing does not conclusively prove that such traces of the 1906 fault may not persist for forty years or even double that period under favorable conditions.

As the rapidity of erosion is directly related to the amount and to the distribution of rainfall the data given below should be considere $\bar{d}$, especially if comparison is to be made with the duration of similar features elsewhere. The mean seasonal rainfall in San Francisco is 23.07 inches, but about 82 per cent. of this falls in the five months of November to March inclusive. The maximum rainfall in any one month since 1906 was 13.79 inches, occurring in January, 1911. The accompanying table will afford detailed information as to the monthly distribution of rainfall during the last seven years.

Rainfall at San Francisco from July, 1906, to June, 1913

From U. S. Weather Bureau Records

\begin{tabular}{|c|c|c|c|c|c|c|c|c|c|c|c|c|c|}
\hline SEASON & JULY & AUG. & SEPT. & OCT. & Nov. & DEC. & JAN. & FEB. & МСH. & APR. & MAY & JUNE & $\begin{array}{l}\text { SEA- } \\
\text { SONAL }\end{array}$ \\
\hline $1906-7 \ldots .$. & 008 & 0.11 & 0.18 & 003 & 1.59 & 6.90 & 4.41 & 302 & 8.42 & 0.11 & 0.04 & 1.28 & $26.1 \tau$ \\
\hline $1907-8 \ldots \ldots$ & $\mathbf{T}$ & 002 & 0.11 & 1.36 & 0.04 & 3.66 & 488 & 5.39 & 0.90 & $0.2 \overline{2}$ & 0.76 & 0.01 & 17.35 \\
\hline $1908-9 \ldots \ldots$ & 0.02 & 0.01 & 0.13 & 0.61 & 1.34 & 2.15 & 10.51 & ก.5.3 & 3.27 & $\mathrm{~T}$ & $\mathrm{~T}$ & $\mathrm{~T}$ & 2557 \\
\hline $1909-10 \ldots \ldots$ & $\mathrm{O}$ & $\mathrm{T}$ & 0.80 & 1.23 & 2.43 & 5.59 & 3.24 & 2.09 & 3.78 & 0.31 & 0.03 & 0.02 & $19.5^{\circ}$ \\
\hline $1910-11 \ldots$. & $\mathrm{T}$ & $\mathrm{O}$ & 0.05 & 0.65 & 0.48 & 1.73 & 13.79 & 3.02 & $4.5 \%$ & 0.89 & 028 & 0.03 & 2549 \\
\hline $1911-12 \ldots \ldots$ & $\mathrm{T}$ & $\mathrm{O}$ & $\mathrm{T}$ & 028 & 0.60 & 2.54 & 2.47 & 0.41 & 4.10 & 1.38 & 1.47 & 0.81 & 14.06 \\
\hline $1912-13 . \ldots$ & $\mathrm{T}$ & $\mathrm{O}$ & 1.25 & 0.49 & 1.94 & 1.30 & 3.84 & 0.43 & $1.4 \%$ & 0.60 & 0.63 & 0.02 & 11.97 \\
\hline Means.... & 0.02 & 0.02 & 0.31 & 1.00 & 2.54 & 4.51 & 4.88 & 3.56 & 3.74 & 1.66 & 0.73 & 0.16 & $23.0 \%$ \\
\hline
\end{tabular}

Means are for a period of 63 years, from 1849-50 to 1912-13.

The data indicating the rainfall for San Francisco undoubtedly apply, so far as the monthly distribution is concerned, to the hills where the fault trace occurs, but the amounts should be materially increased. The hills are from three hundred to four hundred feet higher than San Francisco and are also nearer to the northern ridges of the Santa Cruz Mountains. According to the 
rainfall map, based on long period records and published by the Spring Valley Water Company, ${ }^{3}$ the isohyetal line of forty inches passes through the fault zone area. This would indicate not only a seasonal rainfall of forty inches instead of twenty-three inches but also that the heaviest rainfall in a single month may have reached twenty-five inches. Remembering that in this climate four-fifths of the rainfall is concentrated in five winter months, the persistence of the fault trace is certainly not to be attributed to the aridity of the climate.

Agents of erosion other than water have relatively little effect in this locality. Actual freezing of the ground occurs so seldom and for such short periods of time that it must have but slight influence on the rapidity of erosion. The effect of wind erosion may also be omitted from consideration with grass-covered land receiving the amount of rainfall indicated above and also subject to the ocean fogs during much of the summer.

The original object of the writer. in keeping a part of the fault zone under observation during the last seven years was not for the purpose of determining the persistence of the fault trace. Instead, the observation was undertaken with the idea that erosion might have played quite a part in the development of the small depressions or sags characteristic of the fault zone as it was prior to the movement of 1906. Writers on the San Andreas Fault have quite generally attributed these small depressions to the dropping of minor fault-blocks or wedges along the fault zone, thus classifying them genetically with larger valleys of the graben type.

There is certainly a possibility that in the horizontal movement of the two sides of the fault plane, concave surfaces would in some instances be left opposite each other, leaving a racant space of some appreciable size at a relatively short distance below the surface. Under such conditions there should be a slow downwashing of fragmental material and of soil which would leave a sink-hole at the surface. The observations thus far have not been conclusive. In two or three places slight sinking took place, but these localities have since been plowed, which may possibly interfere with further development. Surface wash in cultivated land will probably fill in a developing sink as rapidly as the depression would grow by underground settling, unless in the extreme instances of the formation of an open channel connecting the bottom of the depression with the cavity below. 
The slowness of surface erosion as indicated by these observations suggests that the theory of the development of "fault-sags" by erosion subsequent to the faulting may yet be found correct in some instances. Sufficient underground water may seldom be present to facilitate such action. The heaviest rainfall for a single month recorded at San Francisco is 24.36 inches. As this indicates a possibility of forty inches in a single month with the heavier rainfall of the fault zone, the greatest rapidity of erosion and the best opportunity for the development of an erosional fault-sag may not have occurred as yet. Any conclusion as to the erosional origin of fault-sags along the rift will have to be deferred until the observations have been carried on for a much longer period and until several years of excessive rainfall have occurred. 




$$
y^{2}=5
$$$$
\text { ह }
$$

is

$\begin{array}{ll}=" & 4 \\ & =\pi\end{array}$

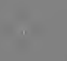

( $)$

8. 


\section{BORROWED}

\section{RETURN CIRCIII ATION REDA DTAAEAIT}

RETURN TO the circulation desk of any University of California Library

or to the

NORTHERN REGIONAL LIBRARY FACILITY Bldg. 400, Richmond Field Station University of California Richmond, CA 94804-4698

ALL BOOKS MAY BE RECALLED AFTER 7 DAYS

- 2-month loans may be renewed by calling (510) 642-6753

- 1-year loans may be recharged by bringing books to NRLF

- Renewals and recharges may be made 4 days prior to due date

DUE AS STAMPED BELOW

$\mathbf{C}^{*}$

JAN 052007 


\section{GENERAL LIBRARY - U.C. BERKELEY}

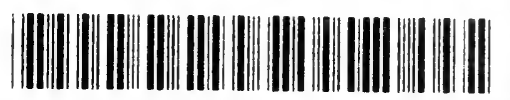

B०00872432

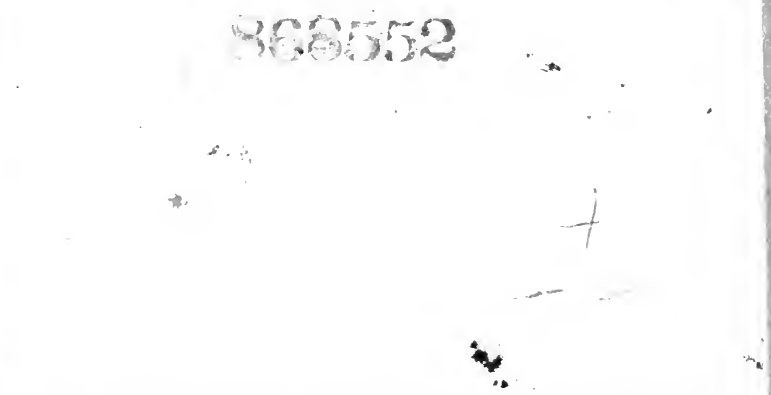

THE UNIVERSITY OF CALIFORNIA LIBRARY 


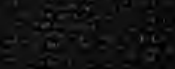

$=-\frac{1}{6}$

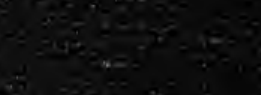

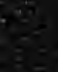

$8=5$

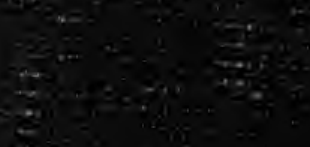

$\frac{2}{4}+\frac{1}{4}$

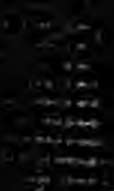

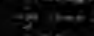

:

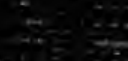

$\frac{1+25}{20}$

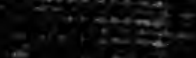

z. 50

$\frac{5+20}{2+20}$

at

son

tan:

$\frac{\pi}{4}$

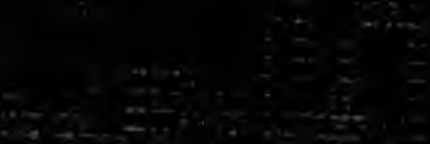

저. 35

$\frac{1}{2}+\frac{13}{4}$

룰

$+$

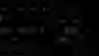

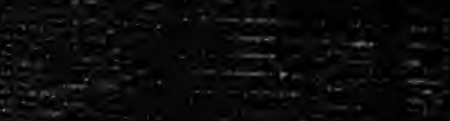

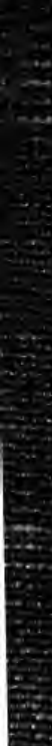

20

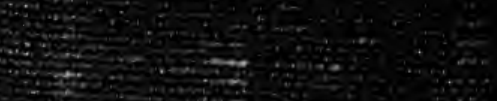

